\title{
A Novel Design of Low-Power 1-Bit CMOS Full-Adder Cell Using XNOR and MUX
}

\author{
Dayadi Lakshmaiah ${ }^{1}$, Dr.M.V.Subramanyam ${ }^{2}$, Dr.K.Sathya Prasad ${ }^{3}$ \\ laxmanrecw@gmail.com \\ ${ }^{1}$ Associate Professor, Nizam Institute of Engineering and Technology, Hyderabad, India. \\ ${ }^{2}$ Principal \& Professor, Santhiram Engineering College, Nandyal, India. \\ ${ }^{3}$ Professor, JNTU Kakinada, Kakinada, India.
}

\begin{abstract}
This paper process a novel design for low power 1-bit CMOS full adder using XNOR and MUX, with reduced number of transistors using GDI cell. The circuits were simulated with supply voltage scaling from $1.2 \mathrm{~V}$ to $0.6 \mathrm{~V} \& 0.6 \mathrm{~V}$ to $0.3 \mathrm{~V}$. To achieve the desired performance of power delay product, area, capacitance the transistors with low threshold voltage were used at critical paths and high threshold voltage at non critical paths. The results show the efficiency of the proposed technique in terms of power consumption, delay and area.
\end{abstract}

\section{KEYWORDS}

Power Delay Product, High and Low threshold voltages, parasitic capacitances, Area.

\section{Council for Innovative Research}

Peer Review Research Publishing System

Journal: International Journal of Management \& Information Technology

Vol. 7, No. 3

editor@cirworld.com

www.cirworld.com, member.cirworld.com 


\section{INTRODUCTION}

Full Adder circuits are popular in Very Large Scale Integration (VLSI) systems and have been employed in various Arithmetic and Logic Applications Viz. addition, subtraction and multiplication. Adders have become integral functional block in Digital signal processing, Image processing and Microprocessors applications and they also form the important circuitry of a CPU, floating point unit, cache and memory access unit. The design and the performance of the full Adder circuits are based on number of transistors, chip area, power dissipation, which has raised the need for low power and high speed, high performance and minimal area circuits [1-3]. The 1-bit full adder circuits proposed by Dan wag et.at[4], Y.Jiang et.at[5], Mahamoud et.at [6], and Lu Jamming et.at [7], it was observed, the circuit occupies low area, consumes low power and operates at lower operating voltage. It is difficult and even obsolete to keep full voltage swing operations the designs consider few transistors for low power consumption. This paper proposes a new implementation of 1-bit full adder with Gate-diffusion-input (GDI) based on MTCMOS and SCCMOS technique by reduction of parasitic capacitance through layout optimization [1113].

\section{PREVIOUS WORK}

The GDI technique is a novel design which is very flexible for digital circuits; it helps in reduction of power and transistor count. The GDI cell has four terminals $G, P, N$ and $D$, and uses two transistors for implementation of complex logic functions. The basic structure of GDI cell is shown in Fig. 1 and Table 1 describes the logical functions of GDI cell.

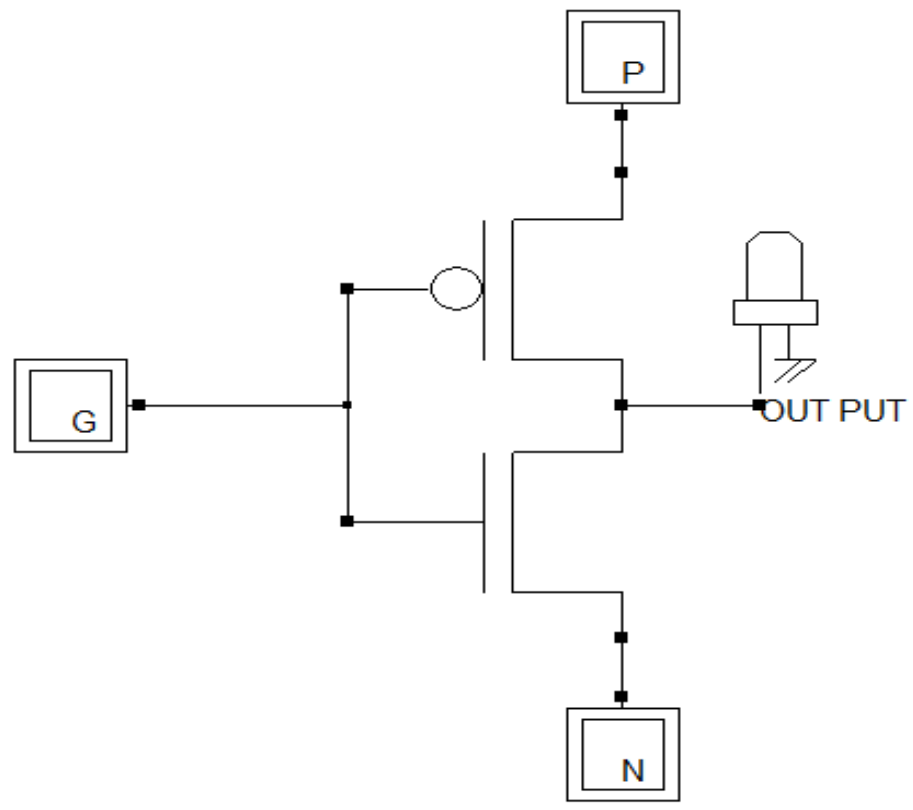

Fig. 1 Basic structure of GDI

Table 1 Logic functions implemented with GDI cell

\begin{tabular}{|c|c|c|c|c|}
\hline $\mathrm{N}$ & $\mathrm{P}$ & $\mathrm{G}$ & $\mathrm{D}=$ output & FUNCTION \\
\hline 0 & $\mathrm{~B}$ & $\mathrm{~A}$ & $\bar{A} B$ & $\mathrm{~F} 1$ \\
\hline $\mathrm{B}$ & 1 & $\mathrm{~A}$ & $\bar{A}+B$ & $\mathrm{~F} 2$ \\
\hline 1 & $\mathrm{~B}$ & $\mathrm{~A}$ & $A+B$ & $\mathrm{OR}$ \\
\hline $\mathrm{B}$ & 0 & $\mathrm{~A}$ & $A B$ & AND \\
\hline $\mathrm{C}$ & $\mathrm{B}$ & $\mathrm{A}$ & $\bar{A} B+A C$ & $\mathrm{MUX}$ \\
\hline 0 & 1 & $\mathrm{~A}$ & $\bar{A}$ & NOT \\
\hline
\end{tabular}


GDI Based Full adder is shown in Fig. 2 and it shows the difference of implementation of logic functions from that shown in [10].

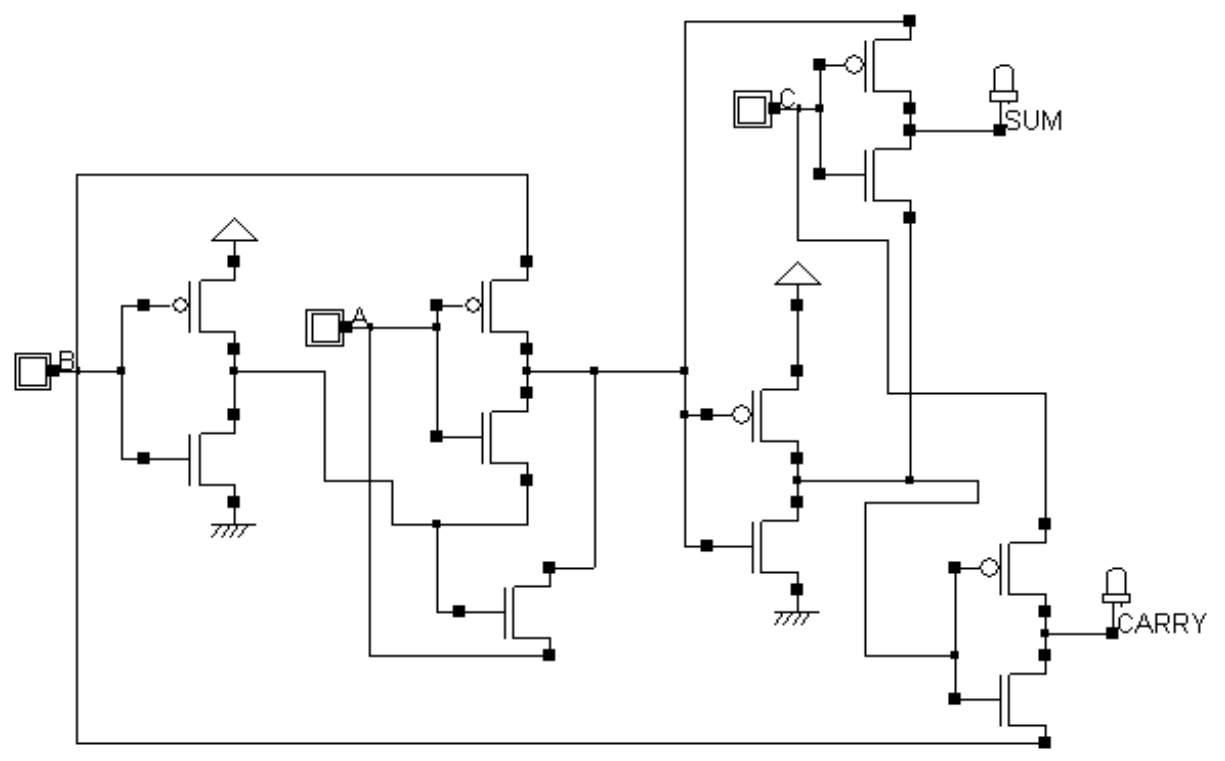

\section{PROPOSED WORKES}

\section{a) Proposed full adder:-1}

A full adder was designed based on reduction of parasitic capacitance, with 10 MOS Transistor for the implementation of logic expression of Eq. (1), Eq. (2). The 1-bit full adder circuit consists of three modules, XNOR-I, XNOR-II and MUX. The XNOR-I and XNOR-II modules are designed using 4 MOS transistors considering two inputs and one output, and MUX module is designed with two MOS transistors for optimum operation. In comparison with design in [10], this technique uses fewer transistors, and in layout design parasitic capacitances are reduced to an optimum value without effecting the operation. Fig. 3 and Fig. 4 show the full adder implementation with 10 MOS transistors. The layout optimization and the simulated waveforms are indicated in Fig. 8 and Fig. 9 respectively.

$$
\begin{aligned}
& \text { Sum }=(A \bar{\oplus} B) C_{i n}+(A \oplus B) \bar{C}_{i n} \\
& C_{\text {out }}=(A \oplus B) C_{i n}+(A \bar{\oplus} B) A
\end{aligned}
$$

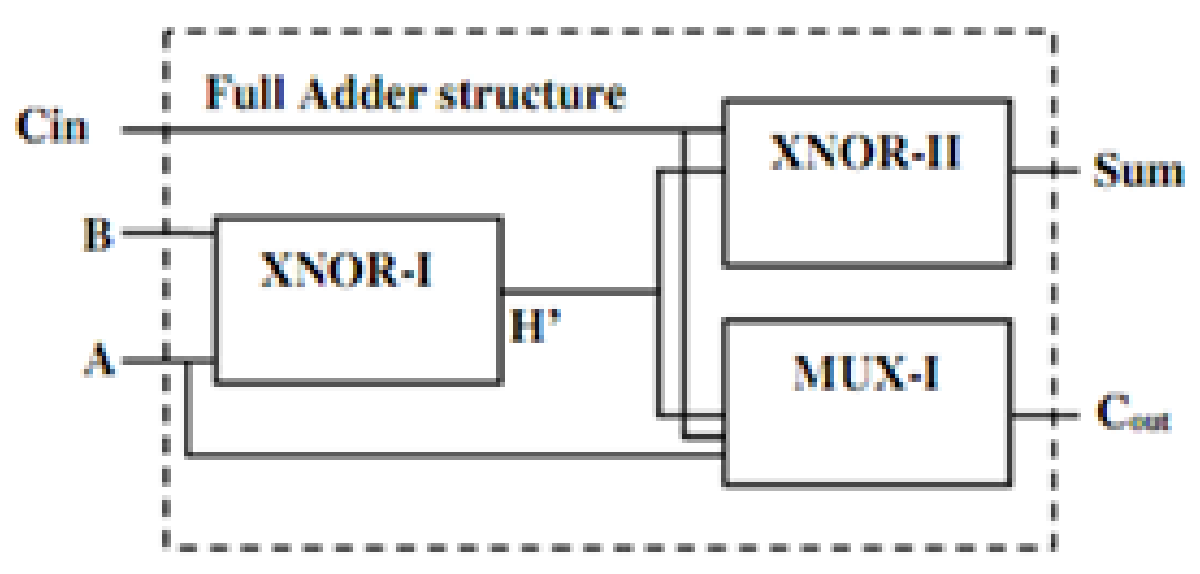

Fig. 3 Structure of Full adder 


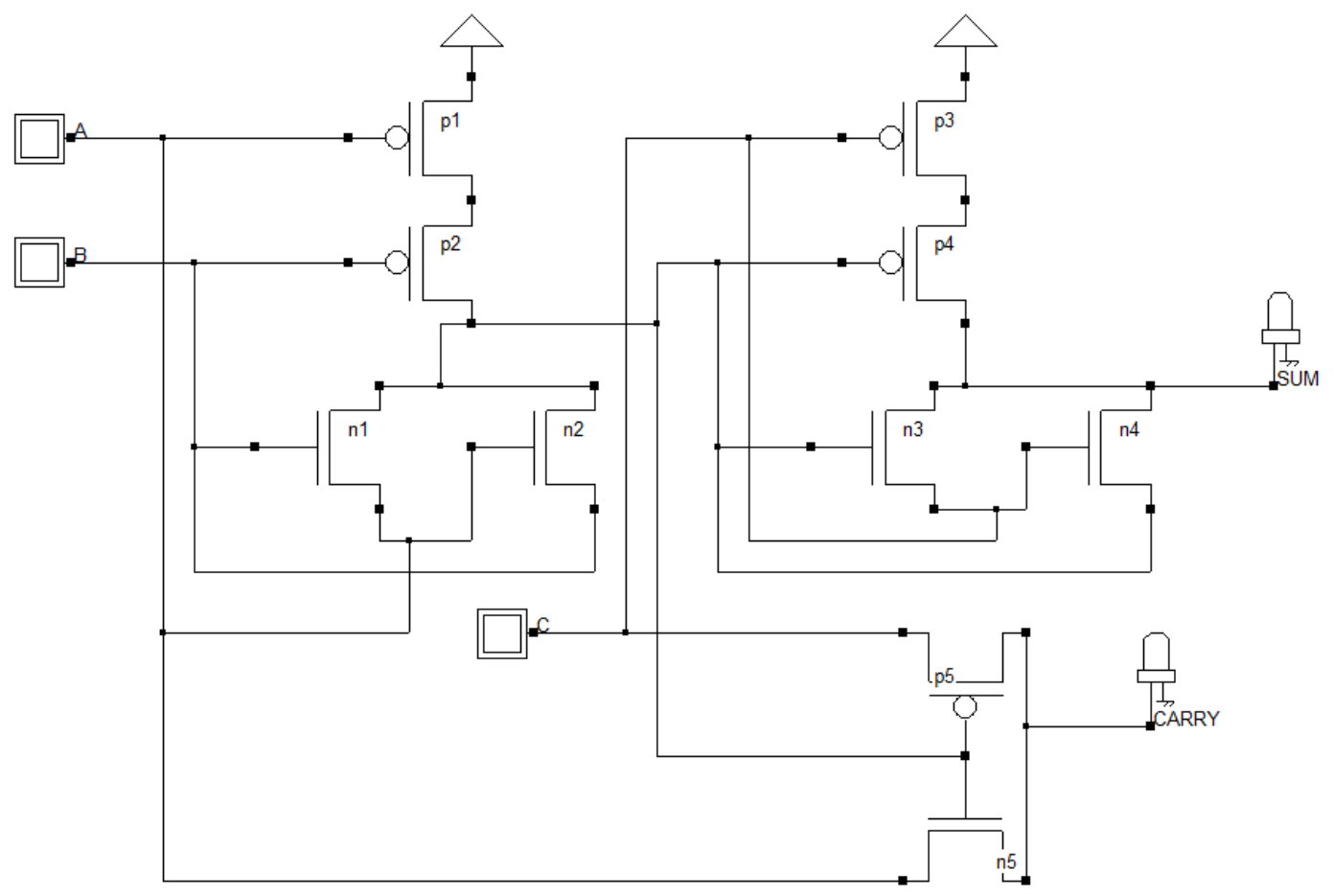

Fig. 4 Full adder implementation with10 MOS transistors

\section{b) Proposed full adder:-2}

An 8 transistor full adders was designed based on reduction of parasitic capacitance, power and area through layout optimization. The full adder consists three modules, XNOR-I, XNOR-II and MUX. The XNOR logic is implemented with 3 MOS transistors and MUX logic with 2 MOS transistors for optimum operation. The implementation of full adder with $8 \mathrm{MOS}$ transistors is shown in fig. 5. Fig. 10 and Fig. 11 represent the layout optimization and simulation waveforms respectively.

\section{c) Proposed full adder:-3}

Another technique for full adder implementation is proposed with 9 MOS transistors. The logical expressions in Eq. (1) and Eq. (2) can be implemented with 3 transistor XOR circuit or 3 transistor XNOR circuit, an inverter and a 2:1 Mux as shown in fig. 6 and fig. 7. Fig. 12 and Fig. 13 represent the layout optimization and simulation waveforms of 9 transistor full adder respectively. Simulation was carried out with supply voltage scaling from $1.2 \mathrm{~V}$ to $0.6 \mathrm{~V} \& 0.6 \mathrm{~V}$ to $0.3 \mathrm{~V}$. The transistors with low threshold voltage at critical paths of the circuits and high threshold voltage at Non critical paths were used to obtain optimized power dissipation \& delay.

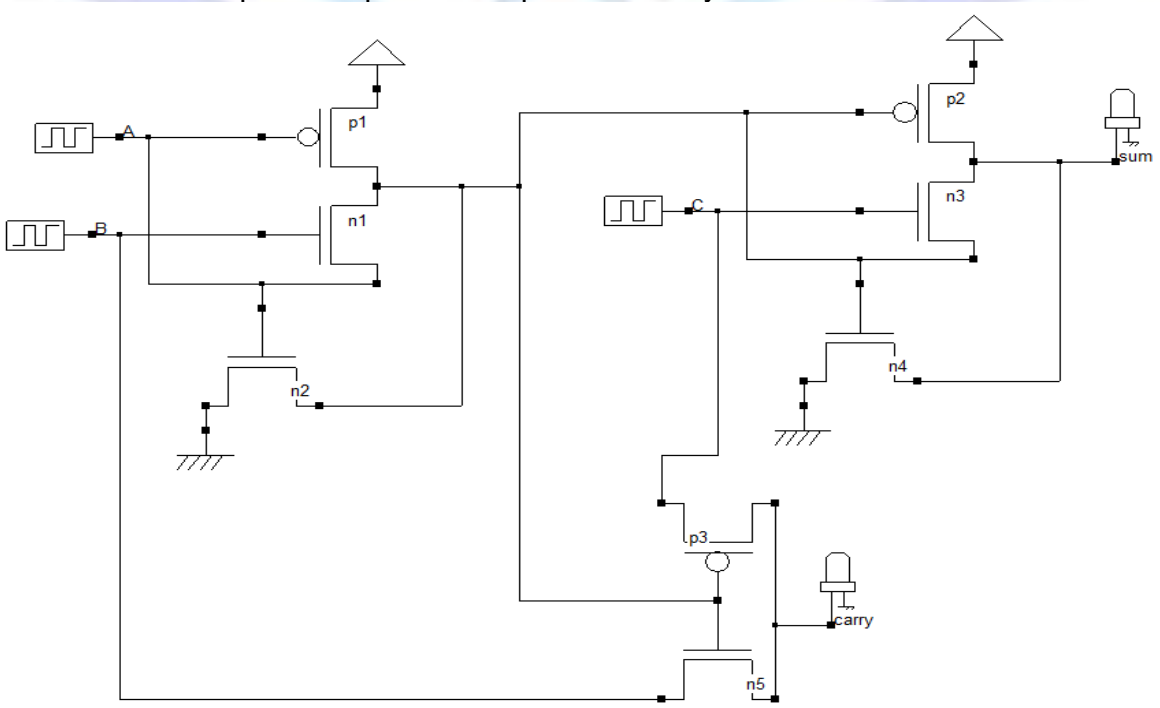

Fig. 5Full adder implementation with 8 MOS transistors 


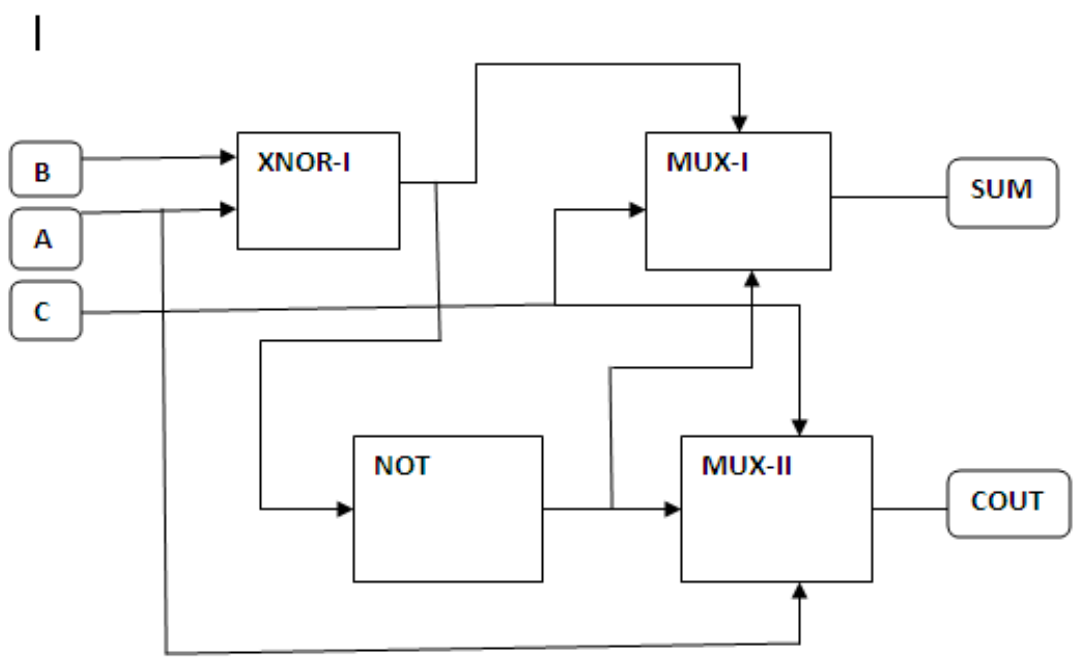

Fig. 6 Structure of Full adder with 9 transistors

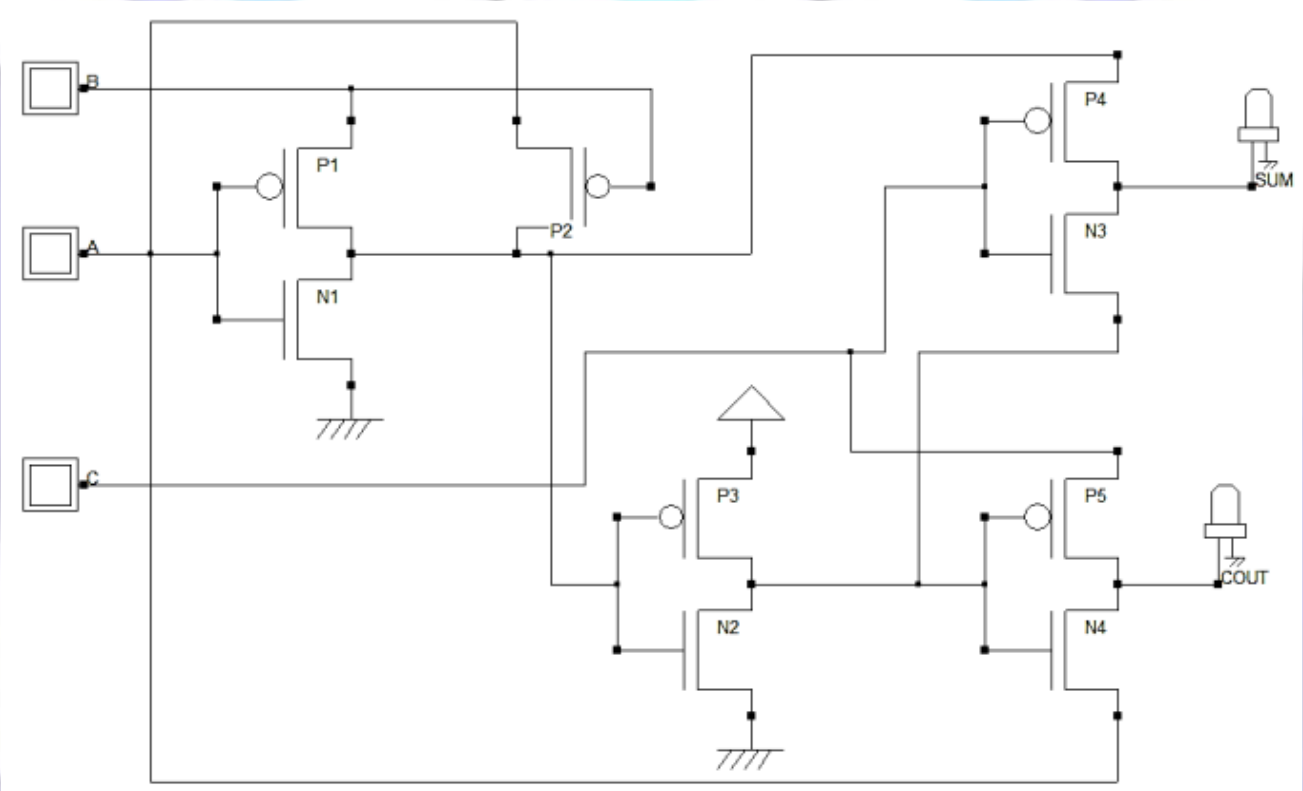

Fig. 7 Full adder implementation with 9 MOS transistors

\section{PERFORMANCE ANALYSIS AND SIMULATION RESULTS.}

The simulations were performed with supply voltage $V_{D D}$ scaling from $1.2 \mathrm{~V}$ to $0.6 \mathrm{~V} \& 0.6 \mathrm{~V}$ to $0.3 \mathrm{~V}$, using 90 Nanometer $(\mathrm{nm})$ Micro wind 3 CMOS layout CAD Tool. The performance was analyzed in terms of delay, power dissipation, power delay product, area and compared with existing techniques. The results are shown in Table 2, Table 3 and Table 4, they indicate good improvement in power, delay and area, which dictates the efficiency the proposed techniques.

Table 2 Performance Analysis of Layout

\begin{tabular}{|c|c|c|c|c|}
\hline Parameter & $\begin{array}{c}\text { Reference Paper } \\
{[10]}\end{array}$ & Proposed work 1 & Proposed work 2 & Proposed work 3 \\
\hline $\begin{array}{c}\text { Number of MOS } \\
\text { Transistors }\end{array}$ & 11 & 10 & 8 & 9 \\
\hline $\begin{array}{c}\mathrm{V}_{\mathrm{DD}} 1=1.2 \mathrm{~V}, \mathrm{~V}_{\mathrm{DD}} 2=1.2 \mathrm{~V} \\
\text { Power }(\mu \mathrm{w})\end{array}$ & 61.269 & 1.819 & 111.2 & 11.83 \\
\hline
\end{tabular}


ISSN 2278-5612

\begin{tabular}{|c|c|c|c|c|}
\hline $\begin{array}{l}\text { High Threshold } \\
\text { voltage }\left(\mathrm{V}_{\mathrm{th}}\right) \\
\text { Power }(\mu \mathrm{w})\end{array}$ & --- & 1.642 & 137 & 11.82 \\
\hline Delay(ns) & 1.380 & 0.21 & 1 & 0.25 \\
\hline $\mathrm{PDP}$ (femito), $\mathrm{V}_{\mathrm{DD}}=1.2 \mathrm{~V}$ & 84.55 & 0.38 & 111 & 2.9 \\
\hline $\begin{array}{c}\mathrm{V}_{\mathrm{DD}} 1=1.2 \mathrm{~V}, \mathrm{~V}_{\mathrm{DD}} 2=0.6 \mathrm{~V} \\
\text { Power }(\mu \mathrm{w})\end{array}$ & --- & 1.697 & 110 & 11.76 \\
\hline $\begin{array}{c}\mathrm{V}_{\mathrm{DD}} 1=0.6 \mathrm{~V}, \mathrm{~V}_{\mathrm{DD}} 2=0.3 \mathrm{~V} \\
\text { Power }(\mu \mathrm{w})\end{array}$ & --- & 0.867 & 33 & 0.427 \\
\hline $\operatorname{Area}\left(\mu \mathrm{m}^{2}\right)$ & 235 & 260 & 84 & 29 \\
\hline $\begin{array}{c}\text { Point A } \\
\text { C } \\
M C \\
C C \\
D C \\
G C\end{array}$ & $\begin{array}{l}7.10 \\
2.53 \\
0.01 \\
0.07 \\
4.50\end{array}$ & $\begin{array}{l}8.37 \\
2.53 \\
0.01 \\
0.53 \\
5.31\end{array}$ & $\begin{array}{c}7.10 \\
2.5 \\
0.00 \\
0.38 \\
4.15\end{array}$ & $\begin{array}{l}1.52 \\
0.58 \\
0.00 \\
0.12 \\
0.82\end{array}$ \\
\hline $\begin{array}{c}\text { Point B } \\
\text { C } \\
\text { MC } \\
\text { CC } \\
\text { DC } \\
\text { GC }\end{array}$ & $\begin{array}{l}9.88 \\
5.41 \\
0.04 \\
0.20 \\
4.28\end{array}$ & $\begin{array}{c}5.6 \\
0.55 \\
0.01 \\
0.26 \\
4.87\end{array}$ & $\begin{array}{c}7.10 \\
2.5 \\
0.00 \\
0.38 \\
4.15\end{array}$ & $\begin{array}{l}0.54 \\
0.20 \\
0.00 \\
0.03 \\
0.31\end{array}$ \\
\hline $\begin{array}{c}\text { Point C } \\
\text { C } \\
M C \\
C C \\
\text { DC } \\
\text { GC }\end{array}$ & $\begin{array}{c}20.56 \\
4.97 \\
0.03 \\
0.13 \\
15.46\end{array}$ & $\begin{array}{l}7.2 \\
2.32 \\
0.01 \\
0.42 \\
5.01\end{array}$ & $\begin{array}{l}2.02 \\
0.51 \\
0.00 \\
0.20 \\
1.31\end{array}$ & $\begin{array}{l}1.20 \\
0.27 \\
0.00 \\
0.03 \\
0.90\end{array}$ \\
\hline $\begin{array}{l}\text { Carry } \\
\text { C } \\
\text { MC } \\
\text { CC } \\
\text { DC } \\
\text { GC }\end{array}$ & $\begin{array}{l}4.63 \\
4.40 \\
0.02 \\
0.23 \\
0.00\end{array}$ & $\begin{array}{l}1.57 \\
1.14 \\
0.00 \\
0.43 \\
0.00\end{array}$ & $\begin{array}{l}1.21 \\
0.74 \\
0.00 \\
0.47 \\
0.00\end{array}$ & $\begin{array}{l}1.20 \\
0.27 \\
0.00 \\
0.03 \\
0.90\end{array}$ \\
\hline $\begin{array}{l}\text { Sum } \\
C \\
M C \\
C C \\
D C \\
G C\end{array}$ & $\begin{array}{l}4.88 \\
4.69 \\
0.01 \\
0.20 \\
0.00\end{array}$ & $\begin{array}{c}3.0 \\
2.3 \\
0.01 \\
0.70 \\
0.00\end{array}$ & $\begin{array}{l}1.72 \\
1.29 \\
0.00 \\
0.43 \\
0.00\end{array}$ & $\begin{array}{l}0.37 \\
0.29 \\
0.00 \\
0.08 \\
0.00\end{array}$ \\
\hline
\end{tabular}


ISSN 2278-5612

Table 3 Performance Analysis of schematic circuits

\begin{tabular}{|c|c|c|c|c|}
\hline Full Adders & Delay $(\mathrm{ns})$ & $\begin{array}{c}\text { Power } \\
\text { Dissipation }(\mu \mathrm{w})\end{array}$ & $\begin{array}{c}\text { Power delay } \\
\text { product } \\
(\text { Femito })\end{array}$ & $\begin{array}{c}\text { Area } \\
\left(\mu \mathrm{m}^{2}\right)\end{array}$ \\
\hline 10 Fa High Vt & 1.260 & 17.53 & 22 & 308 \\
\hline 10 Fa Low Vt & 1.110 & 11.54 & 12 & 252 \\
\hline 10 Fa High \& Low Vt & 1.170 & 17.53 & 21 & 315 \\
\hline 9 Fa High Vt & 1.730 & 9.72 & 16 & 253 \\
\hline 9 Fa Low Vt & 0.860 & 9.62 & 9 & 234 \\
\hline 9 Fa High \& Low Vt & 1.600 & 10.14 & 15.6 & 258 \\
\hline 8 Fa High Vt & 1.020 & 226 & 230 & 256 \\
\hline 8 Fa Low Vt & 0.890 & 191 & 171 & 204 \\
\hline 8 Fa High \& Low Vt & 0.880 & 182 & 160 & 192 \\
\hline
\end{tabular}

Table 4 Performance Analysis of Schematic Circuits

\begin{tabular}{|c|c|c|c|}
\hline & Proposed work 1 & Proposed work 2 & Proposed work 3 \\
\hline $\begin{array}{c}\text { Power }(\mu \mathrm{w}) \\
\text { VDD1 }=1.2 \mathrm{~V}, \mathrm{VDD} 2=0.6 \mathrm{~V}\end{array}$ & 4.027 & 3.422 & 132 \\
\hline $\begin{array}{c}\text { Power }(\mu \mathrm{w}) \\
\text { VDD1 }=0,6 \mathrm{~V}, \mathrm{VDD} 2=0.3 \mathrm{~V}\end{array}$ & 1.152 & 3.20 & 3.422 \\
\hline Area $\left(\mu \mathrm{m}^{2}\right)$ & 287 & 210 & 174 \\
\hline
\end{tabular}

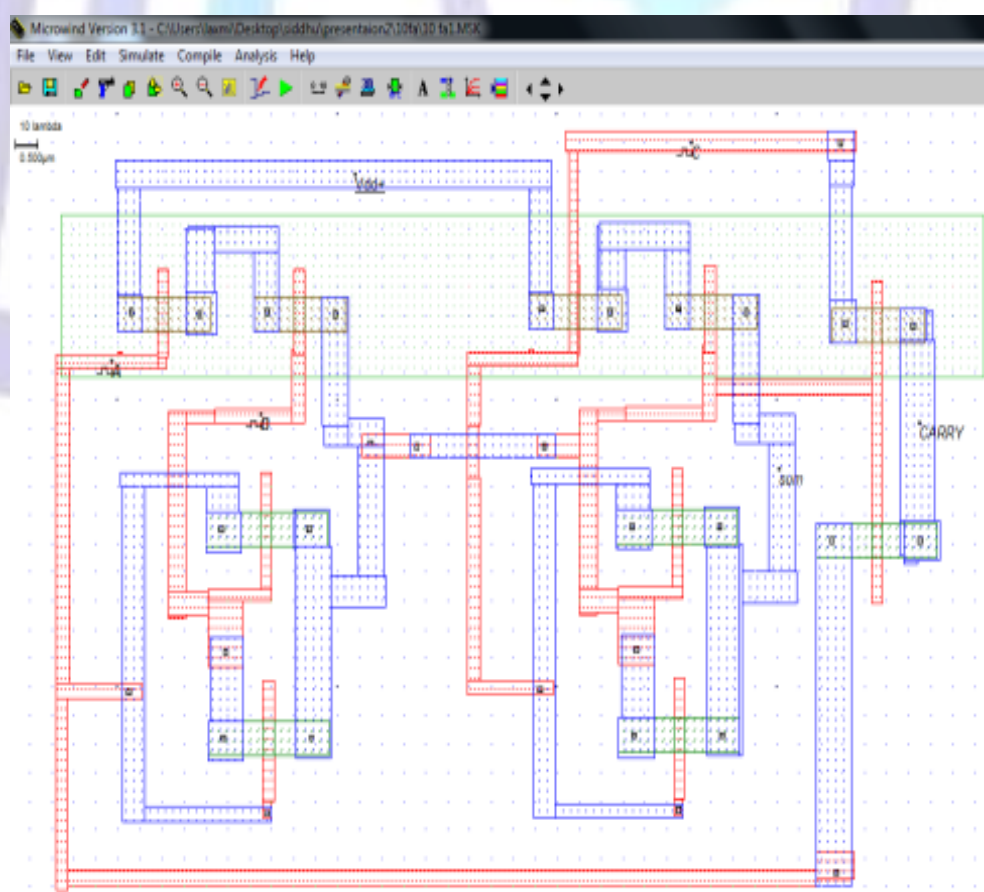

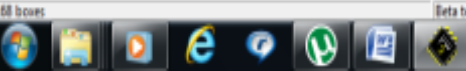

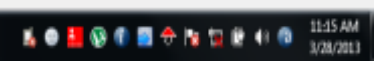

Fig. 8 Layout optimization for proposal 1 


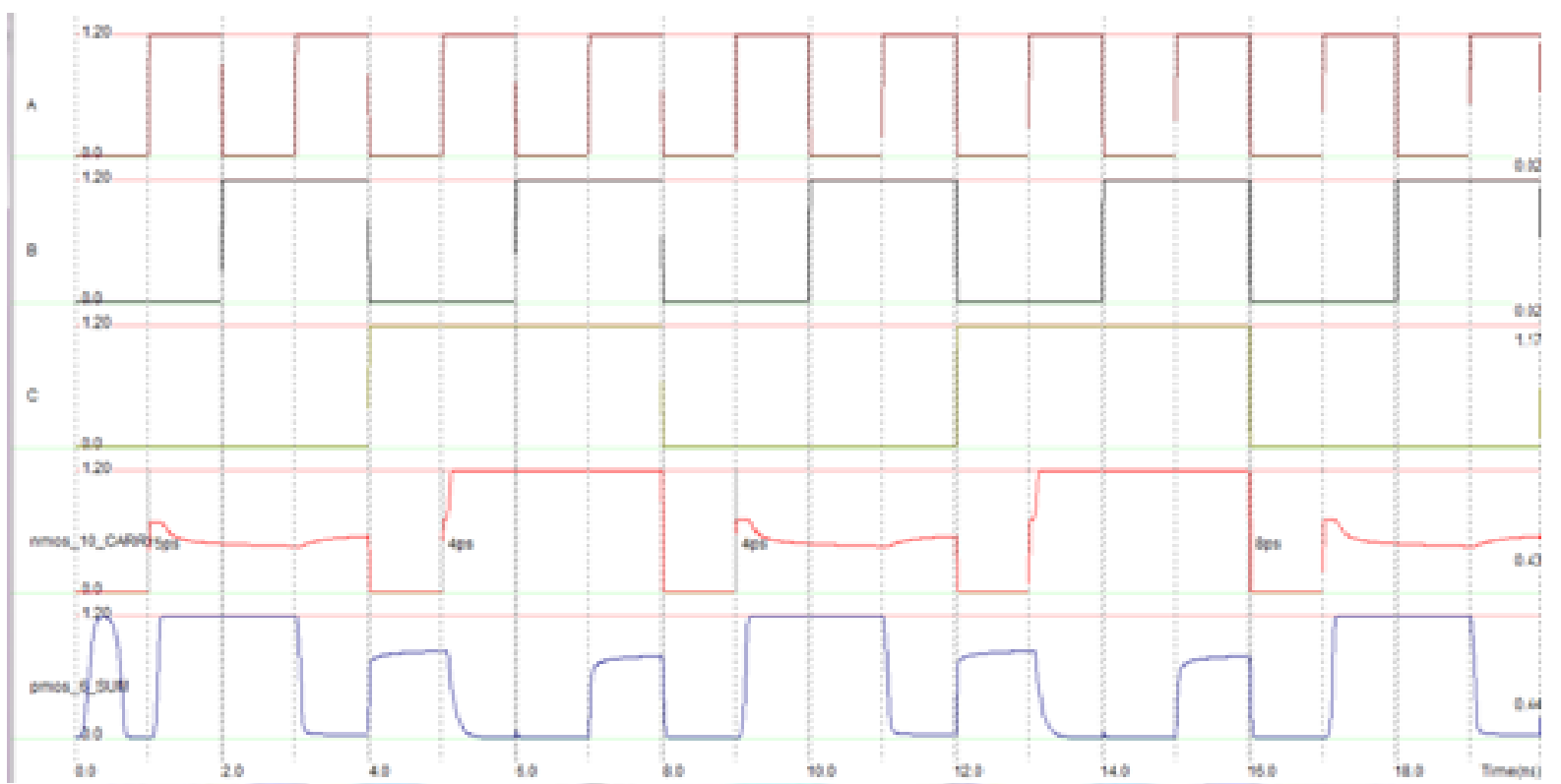

Fig. 9 Simulation results for proposal 1

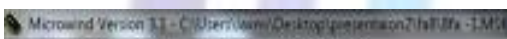

Fite Veor filit Smuate Compile anabigk Help

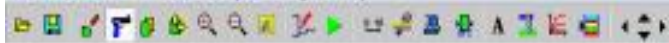

thes

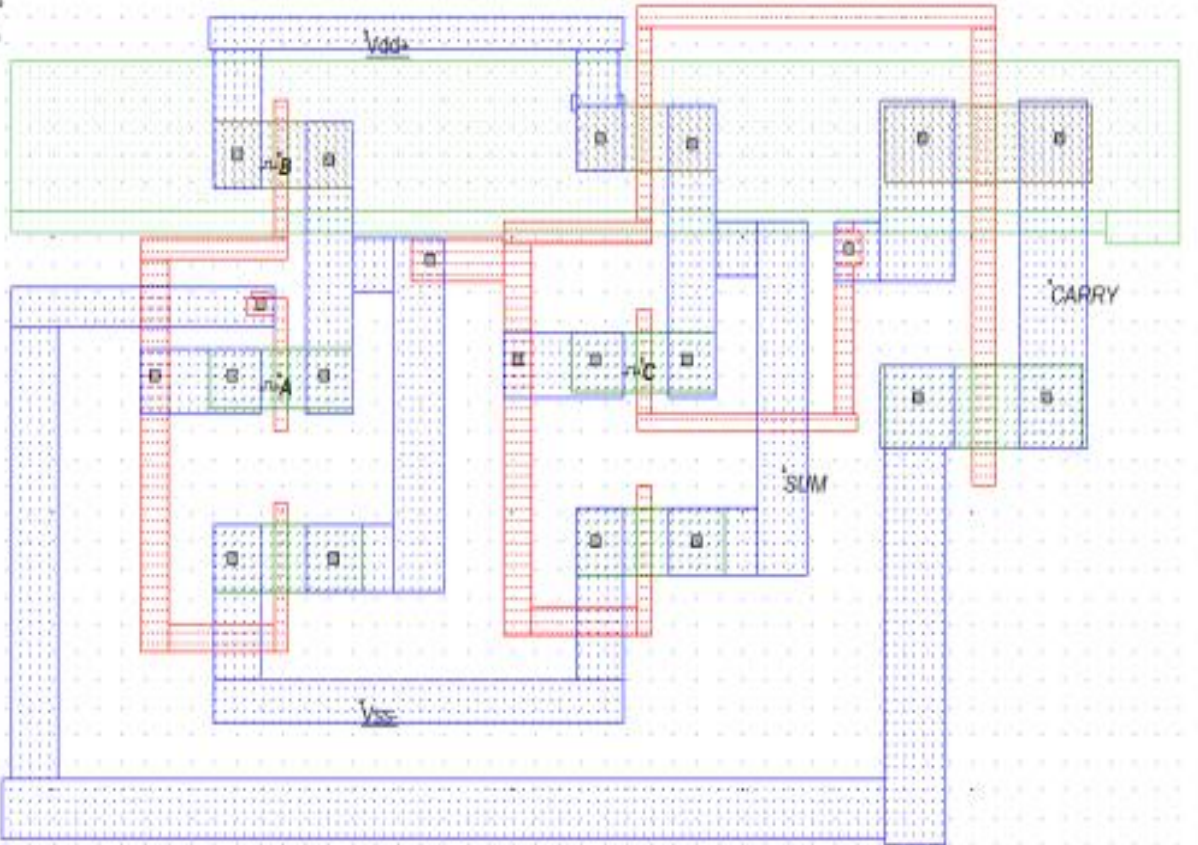




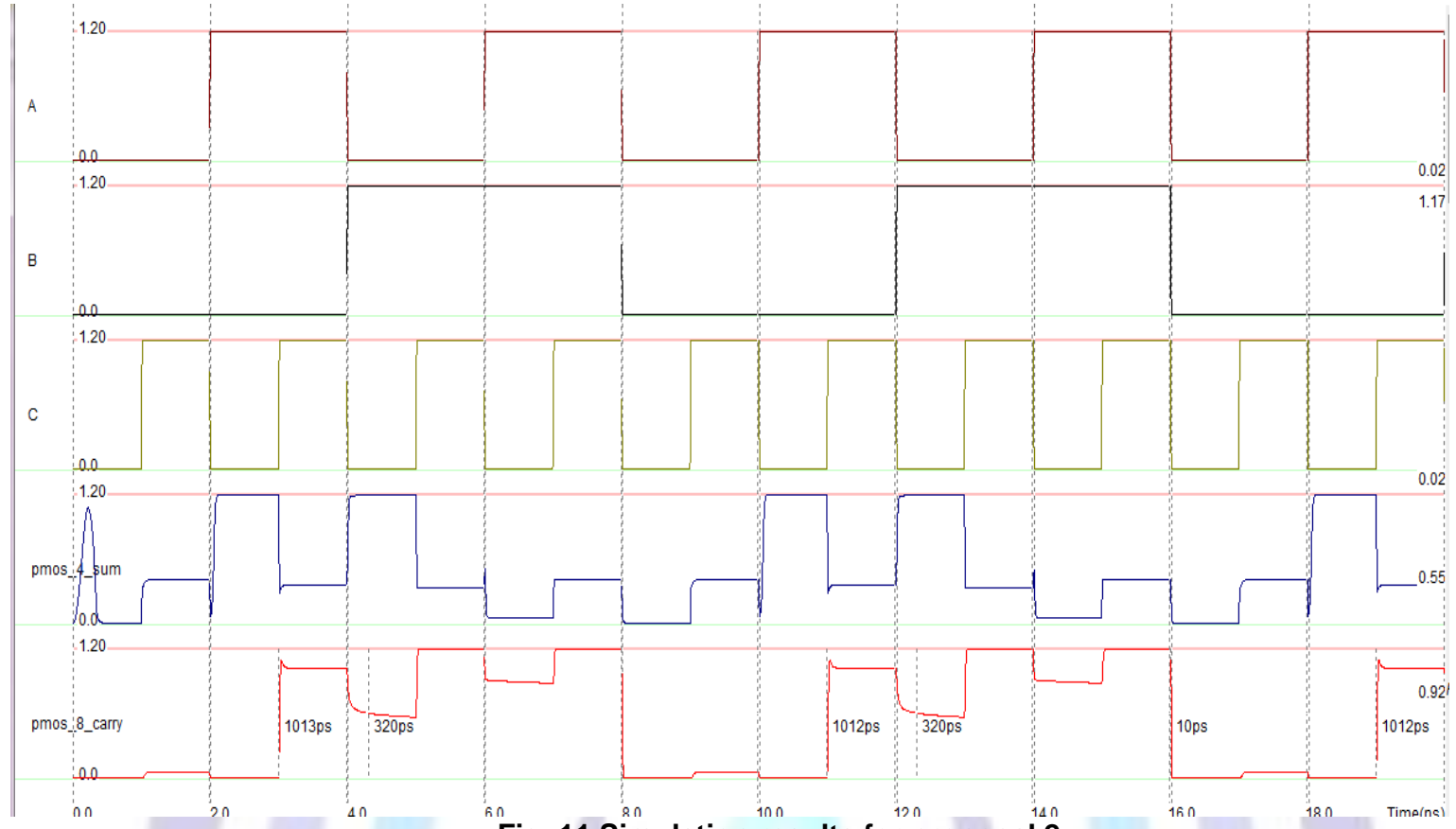

Fig. 11 Simulation results for proposal 2

Microwind Version 3.1 - C:Documents and SettingslecelabiDesktopllax phdlfulladder newlfa9.MSK

File View Edit Simulate Comple Analysis Help

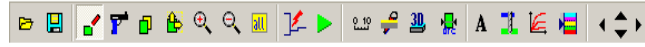

$\stackrel{.51 \mathrm{ambda}}{\stackrel{0.250 \mathrm{~mm}}{2}}$

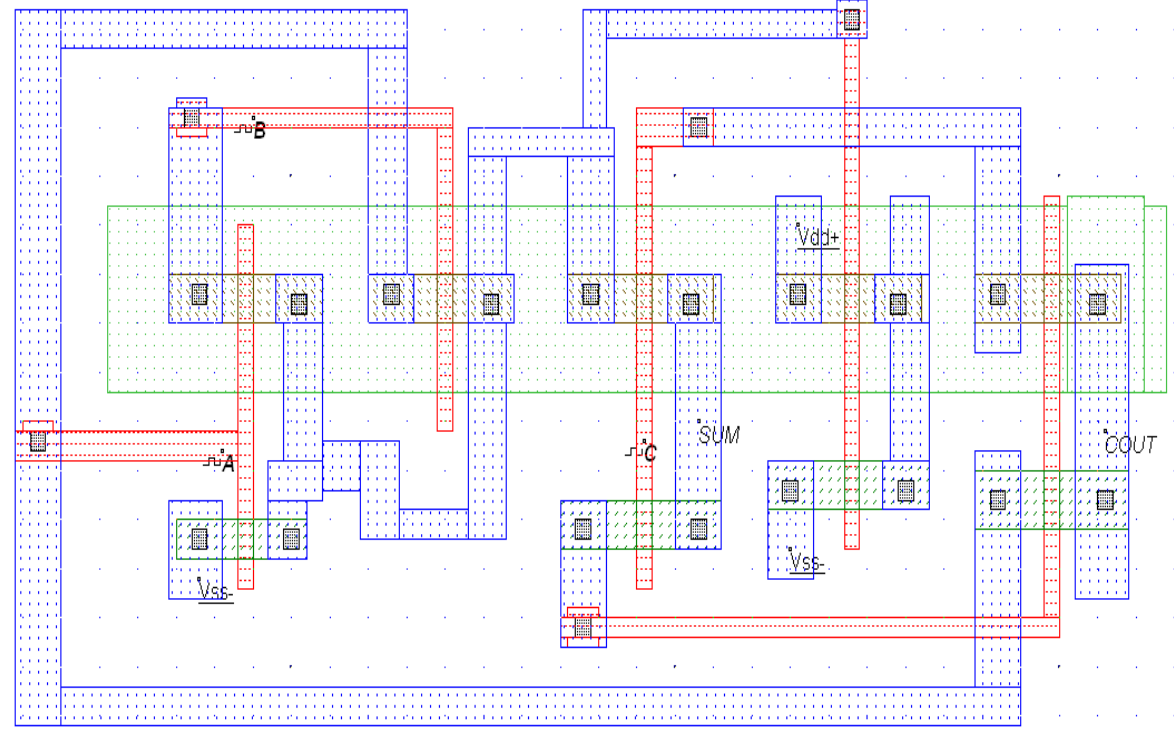




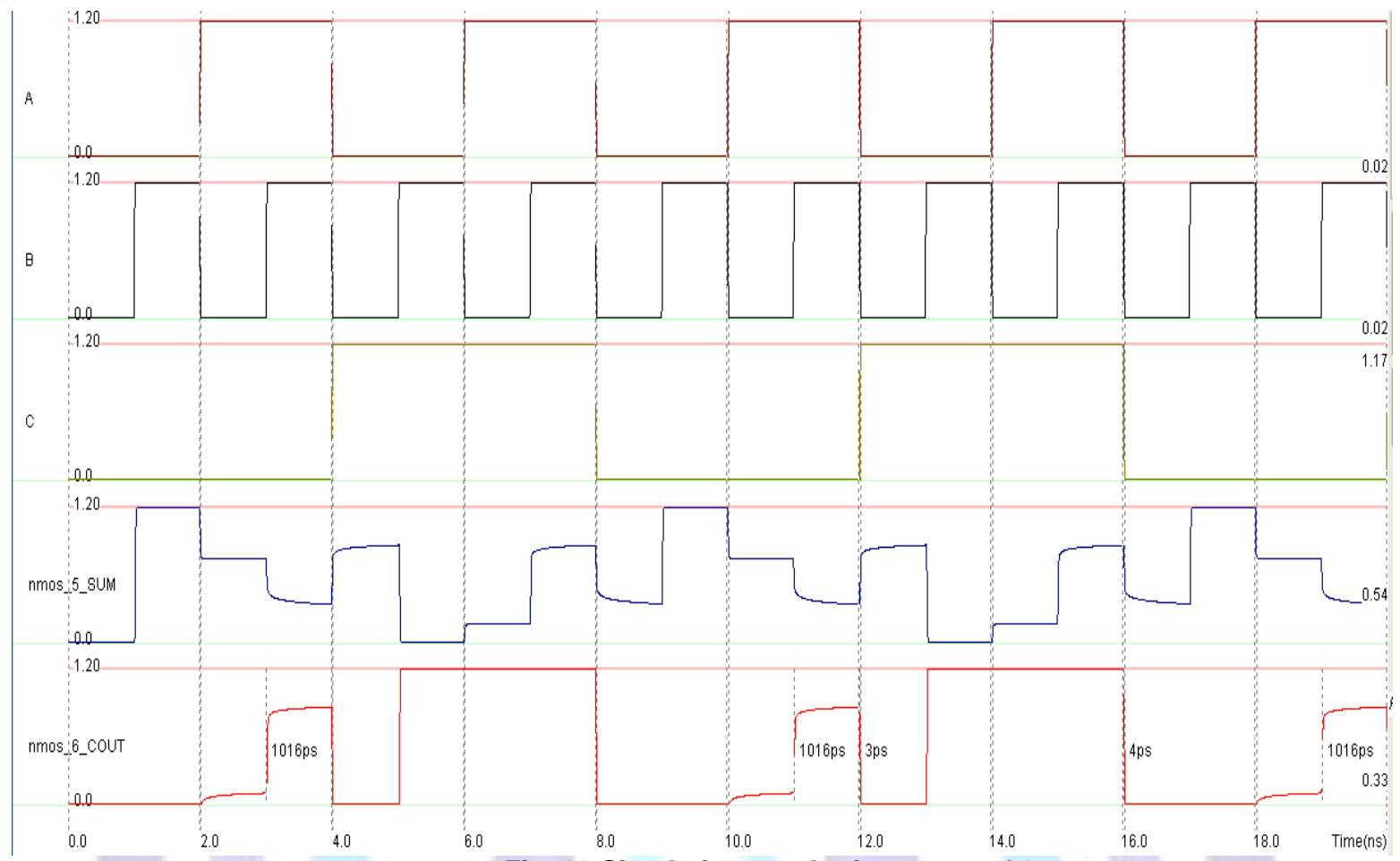

\section{CONCLUSIONS}

The present paper demonstrated the improvement in parameters Viz. area, power, delay and capacitances with reduction in number of transistors to implement Full adder circuits. The design architecture shows good reduction in area, power consumption. The simulations were performed using 90nm Micro wind 3 CMOS layout CAD Tool. The performance of ALU improves by incorporating the proposed technique for adders in it. Still the performance of Full adder can be improved by incorporating techniques which support reduced transistor implementations.

\section{REFERENCES}

[1] Rabaey J. M., A. Chandrakasan, B. Nikolic, Digitallntegrated Circuits, ADesign Perspective, $2^{\text {nd }}$ edition, 2002 , PrenticeHall, EnglewoodCliffs, NJ.

[2] UyemuraJ.,CMOSLogicCircuitDesign,Kluwer, 1999,

[3] N. Weste,K.Eshragian,PrinciplesofCMOS VLSIDesign: ASystemsPerspective,Addison-Wesley, 1993.

[4] DanWang,MaofengYang,WuCheng,Xuguang Guan, ZhangmingZhu,YintangYang,"NovelLow PowerFull Adder Cells in 180nm CMOS Technology", 4th IEEE Conference on Industrial Electronics and Applications, ICIEA2009, pp 430-433.

[5] Y.Jiang,A.A.Sheraidah,Y.Wang,E.Sha, and J.G.Chung, "Anovelmultiplexer-basedlow powerfulladder, "IEEETrans. CircuitsSyst.Il.vol.51,pp.345-348, Jul.2004.

[6] Mahmoud, H.A.; Bayoumi, M.A, "A 10-transistor low- power high speed full adder cell", IEEE International Symposium on Circuits and Systems, vol-1, pp. 43-46,1999.

[7] Lu Junming; Shu Yan; Lin Zhenghui; Wang Ling,"ANovel 10-transistor Low-power High-speed Full adder cell", Proceedings of 6th International Conference on Solid-Stateand Integrated-CircuitTechnology,vol2,pp.1155-1158,2001.

[8] R. Zimmermann, W. Fichtner, Low-powerlogic styles:CMOS versuspasstransistor logic,IEEEJ. SolidStateCircuits,32(7),pp.1079-1090,1997.

[9] KYano,YSasaki,KRikinoandKSeki,Top-downpasstransistorlogicdesign, IEEEJ.Solid-StateCircuits,vol.31,pp.792-803,1996

[10] DeepaSinha,TriptiSharma,K.G.Sharma,Prof.B.P.Singh Design and analysis of low power 1 bit full adder cell IEEE paper 2011.

[11] Dayadi.Lakshmaiah, Dr.M.V.Subramanyam,Dr.K.Satya Prasad, A Novel low power 1-Bit Full adder cell with the Gate Diffusion Input Based on MTCMOS \& SCCMOS. IJAST march 2012 London,U.K

[12] Dayadi.Lakshmaiah,Dr.M.V.Subramanyam,Dr.K.SatyaPrasad, Low power cmos 1-Bit Full adder cell. Based on voltage scaling IOSR-JECE July 2012.Australiya 
[13] Dayadi.Lakshmaiah, Dr.M.V.Subramanyam,Dr.K.SatyaPrasad, Low power cmos 1-Bit Full adder cell. Based on reduction of capacitance through layout optimization IJSER 2012 France.

\section{Authors Biography}

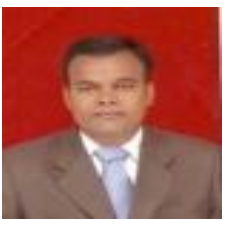

Dayadi.Lakshmaiah is the Research scholar at JNTUK, Kakinada, Andhra Pradesh, India. He Received B.Tech Degree in ECE from National Institute of Technology, Warangal (RECW) and M.Tech (DSCE) Degree from JNTUA Anantapur. He has published 9 technical papers in International Journals. .His area of interest is in Low Power VLSI. India.

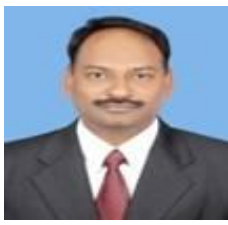

Dr. M.V. Subramanyam, currently working as The Principal of Santhiram Engineering College, Nandyal, Andhra Pradesh, India. He has 24 years of Experience in Teaching. He is the authored of 4 text books. He published more than 65 Technical papers in various National and International Journals and conference, $\mathrm{He}$ is the Editorial Member for the 4 International journals and 3 National Journals. His area of interest is Adhoc Wireless Networks, Cellular and Mobile Communications. He has doned M.Tech and Ph.D from JNTU, Hyderabad. He has completed 5 research projects sponsored by the $\mathrm{IE}(\mathrm{I})$, India and currently one research project in hand funded by AICTE, New Delhl

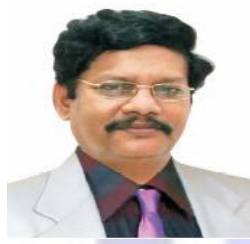

Dr. K. Satya Prasad, is professor of JNTUK, Kakinada. He has more than 34 years of experience in teaching and 25 years of $R \& D$. He is an expert in Digital Signal Processing.12 scholars had completed their Ph.D under his guidance and 10 scholars are pursuing their research.. He is the author of Electronic Devices and Circuits text book. He held different positions in his career like Head of the Department, vice principal and principal for JNTU Engineering College (JNTUK). He published more than 60 technical papers in National and International Journals and conferences. He also received best Teacher Award from Govt of Andhra Pradesh in 2010. He received B.Tech Degree in ECE from JNTU, Anantapur, M.E (Communication Systems) Degree from University of Madras, and Ph.D (signal Processing) Degree from the Indian Institute of Technology Madras, India. 